\title{
Faktor-faktor yang mempengaruhi penggunaan aplikasi online pada pelaku usaha mikro kecil dan menengah di Kota Jambi
}

\author{
Etik Umiyati*; Erni Achmad \\ Prodi Ekonomi Pembangunan, Fak. Ekonomi dan Bisnis, Universitas Jambi \\ *E-mail korespondensi: Umiyati.etik@yahoo.com
}

\begin{abstract}
Digital developments make micro, small and medium enterprises must adjust to technological advances. the adoption of digital economic use of MSME actors is still relatively low. This is caused by several factors. The purpose of this study is to analyze the factors that influence the use of digital economy in SMEs in the City of Jambi. This study uses primary data with a purposive random sampling technique. The number of samples is 105 respondents. The analytical tool used is binary logit regression. Dependent variables are business actors who use digital (score $=1$ ) and those who do not use digital (score = $0)$. The independent variable is household characteristics and business characteristics. From the results of the study obtained factors that influence MSMEs in using the digital economy are business type variables, information technology training, partnerships, age, education level and internet network.
\end{abstract}

Keywords: Digital economy, MSME, Binary logit regression

\begin{abstract}
Abstrak
Perkembangan digital membuat usaha mikro kecil dan menengah harus menyesuaikan diri dengan kemajuan teknologi. Adopsi pemanfaatan ekonomi digital pelaku UMKM masih relatif rendah. Ini disebabkan oleh beberapa faktor. Tujuan penelitian ini adalah menganalisis faktor-faktor yang mempengaruhi pemanfaatan ekonomi digital pada UKM di Kota Jambi. Penelitian ini menggunakan data primer dengan teknik purposive random sampling. Jumlah sampel sebanyak 105 responden. Alat analisis yang digunakan adalah regresi logit biner. Variabel terikat adalah pelaku usaha yang menggunakan digital (skor = 1) dan yang tidak menggunakan digital (skor $=0$ ). Variabel bebas adalah karakteristik rumah tangga dan karakteristik usaha. Dari hasil penelitian didapatkan faktor-faktor yang mempengaruhi UMKM dalam memanfaatkan ekonomi digital adalah variabel jenis usaha, pelatihan teknologi informasi, kemitraan, umur, tingkat pendidikan dan jaringan internet.
\end{abstract}

Kata kunci: Ekonomi digital, UMKM, Regresi logit biner

\section{PENDAHULUAN}

Potensi industri digital di Indonesia tidak bisa dianggap sebelah mata. Dari hasil survei APJII (Asosiasi Penyelenggara Jasa Internet di Indonesia) pada tahun 2016 sebanyak 132.7 juta jiwa penduduk Indonesia (atau 51\% dari total jumlah penduduk) telah mengakses internet dan sebanyak $70.4 \%$ telah melakukan aktivitas transaksi perbankan secara online serta $49 \%$ dari pengguna internet sudah melakukan pembayaran dengan memanfaatkan fasilitas digital banking seperti ATM, internet banking, kartu kredit, SMS banking, dan e-money. 
Usaha Mikro Kecil dan Menengah (UMKM) merupakan kelompok pelaku ekonomi terbesar dalam perekonomian di Indonesia dan telah terbukti menjadi kunci pengaman perekonomian nasional dalam masa krisis ekonomi serta menjadi desiminator pertumbuhan ekonomi pasca krisis. UMKM di Indonesia memberikan kontribusi dalam perekonomian, hal ini dapat dilihat dari perkembangan jumlah unit usaha yang mencapai 62,92 juta unit usaha atau 99,92\% dari total unit usaha. Kontribusi UMKM terhadap PDB mencapai $60 \%$ serta mampu menyerap tenaga kerja 116,73 juta atau $97,02 \%$ dari total angkatan kerja yang bekerja.(Bank Indonesia,2017). Disisi lain perkembangan UMKM di Indonesia juga menghadapi berbagai hambatan usaha baik yang bersifat eksternal dan internal. Hal yang berkaitan dengan eksternal, antara lain : a) akses pembiayaan usaha yang terbatas, b) mahalnya biaya infrastruktur, dan c) layanan birokrasi yang tidak efisien. Dan yang berkaitan dengan internal, antara lain : a) kelembagaan dan Sumber Daya Manusia (SDM), b) pemasaran dan teknologi, c) modal intelektual.

Masalah yang dihadapi dan sekaligus menjadi kelemahan UMKM adalah kurangnya akses informasi, khususnya informasi pasar (Ishak, 2005). Hal tersebut menjadi kendala dalam hal memasarkan produk-produknya, karena dengan terbatasnya akses informasi pasar akan mengakibatkan rendahnya orientasi pasar dan lemahnya daya saing di tingkat global. Informasi yang terbatas mengenai pasar menjadikan UMKM tidak dapat mengarahkan pengembangan usahanya secara jelas dan fokus, sehingga perkembangannya mengalami stagnasi.

Indonesia memiliki potensi besar dalam kegiatan ekonomi digital, namun pemanfaatan internet saat ini didominasi untuk kegiatan media sosial. Adopsi digital oleh pelaku UMKM masih relatif rendah. Penelitian yang dilakukan oleh Kristiansen et al. (2005) di Tanzania menemukan bahwa hanya 3,3\% UKM yang menggunakan Internet. Baron (2003) dalam sebuah studinya menemukan bahwa penggunaan media, termasuk Internet, untuk mengakses informasi akan membuat peluang untuk adaptasi usaha dengan perkembangan yang terjadi. Jika hal ini yang terjadi, maka pada tingkat tertentu, daya saing UKM akan semakin kuat.

Pada era digital UMKM mempunyai kesempatan untuk meningkatkan kinerja dengan cara memperluas jaringan usaha menggunakan internet. Kemudahan mengatur usaha menggunakan software atau aplikasi juga dapat dirasakan di era digital ini. Pemilik usaha yang sudah terkoneksi dengan internet ternyata bisa merasakan manfaat lebih banyak. Mereka bisa mendapatkan akses secara lebih luas dalam mengembangkan usahanya.

Jumlah UMKM di Indonesia pada tahun 2018 mencapai 59,2 juta, akan tetapi yang tersentuh dengan teknologi hanya 18 persen atau 3,9 juta UMKM. Pemberdayaan UMKM di tengah arus globalisasi dan tingginya persaingan membuat UMKM harus mampu menghadapi tantangan global, seperti meningkatkan inovasi produk dan jasa, pengembangan sumber daya manusia dan teknologi, serta perluasan area pemasaran. Hal ini perlu dilakukan untuk menambah nilai jual UMKM itu sendiri, utamanya agar dapat bersaing dengan produk-produk asing yang kian membanjiri sentra industri dan manufaktur di Indonesia, mengingat UMKM adalah sektor ekonomi yang mampu menyerap tenaga kerja terbesar di Indonesia (Sudaryanto,2011).

Promosi UMKM selama ini lebih banyak dilakukan melalui pameran-pameran bersama dalam waktu dan tempat yang terbatas, sehingga hubungan maupun transaksi dengan konsumen kurang bisa dijamin keberlangsungannya. UMKM perlu mengembangkan sarana promosi online untuk mengenalkan produknya secara luas. Menurut Kiran et al. (2012), UMKM dapat menggunakan internet dan digital ekonomi 
sebagai alat promosi yang efisien untuk mengenalkan produk, pendekatan kluster industri untuk membentuk jaringan usaha sehingga dapat menjangkau pasar potensial, serta fokus terhadap inovasi untuk membangun reputasi UMKM. Berdasarkan hasil survei yang dilakukan Jenny,C,A, and Isaac,M. (2010) menunjukkan bahwa kepemilikan ponsel dapat meningkatkan akses pasar, serta memberikan kontribusi pada efisiensi dalam melakukan bisnis. Selanjutnya Mbogo (2010) melihat dampak sistem e-money terhadap UKM di Kenya menunjukkan sektor ini berkontribusi dalam menciptakan lapangan pekerjaan di sektor informal sebesar 80,6 \%. Data Delloite Access Economics, menunjukkan lebih dari sepertiga UKM di Indonesia (36\%) masih offline, sepertiga lainnya (37\%) hanya memiliki kemampuan online yang sangat mendasar seperti komputer atau akses broadband. Hanya sebagian kecil (18\%) yang memiliki kemampuan online menengah (menggunakan web atau medsos) dan kurang dari sepersepuluh (9\%) adalah bisnis online lanjutan dengan kemampuan e-commerce. Data dari McKinsey Global Institute menunjukkan hanya 5\% UKM yang sudah mampu bertransaksi online.

Jumlah UMKM yang menggunakan aplikasi on-line masih sangat rendah, ini disebabkan oleh beberapa faktor. Faktor-faktor yang mempengaruhi UMKM dalam mengadopsi tehnologi dan informasi pada umumnya bersumber dari karakteristik pemilik usaha. Menurut Adnan Mustafa AlBar \& Md. Rakibul Hoque (2017) bahwa faktor-faktor yang mempengaruhi adopsi TIK dikalangan UKM di Arab Saudi adalah keuntungan relatif, dukungan top manajemen, budaya, lingkungan, inovasi dan pengetahuan ICT. Selanjutnya Syed Zamberi Ahmad,et al (2015) juga meneliti faktor-faktor yang menentukan adopsi ecommerce pada UKM di Malaysia adalah keuntungan relatif, pengetahuan dan keahlian pemilik, karakteristik manajemen dan lingkungan eksternal. Menurut penelitian Wanyoike, D. M., et al (2012) bahwa faktor-faktor yang mempengaruhi perusahaan kecil dalam mengadopsi e-commerce di Kenya adalah rutinitas kerja, koordinasi yang efisien antar berbagai mitra atau institusi terkait, peningkatan produktivitas. Taylor \& Owusu (2012) mengidentifikasi faktor-faktor yang mempengaruhi adopsi internet dan e-commerce pada industri handycraf di Ghana. Adapun faktor-faktor tersebut adalah karakteristik pemilik/manajer, karakteristik perusahaan, infrastruktur, tehnologi, sosial ekonomi budaya dan politik.

Perkembangan jumlah UMKM di Provinsi Jambi terus mengalami peningkatan. Pada tahun 2017 mencapai 100.898 dengan rincian 87.669 usaha mikro, 12.674 usaha kecil dan 555 unit usaha menengah, atau terjadi peningkatan 2,8 persen dari tahun sebelumnya. Usaha Mikro Kecil Menengah (UMKM) di Provinsi Jambi mendominasi aktivitas ekonomi dengan proporsi sekitar 98,61 persen. Sementara itu, Usaha Menengah Besar (UMB) sebanyak 4.394 usaha/perusahaan, dan terkonsentrasi di Kota Jambi (47,16 persen). Wilayah yang menjadi sentra perekonomian Provinsi Jambi ini memegang peranan penting dalam tumbuh suburnya berbagai aktivitas ekonomi terutama yang menghasilkan jasa-jasa. Sebaran usaha/perusahaan antar kabupaten/kota menunjukkan 62.538 usaha/ perusahaan berlokasi di Kota Jambi atau 19,73 persen terhadap seluruh perusahaan di Provinsi Jambi. Meskipun jumlah unit usaha mengalami peningkatan, tetapi belum semua pelaku UMKM dapat mengakses digital ekonomi. Kebanyakan UMKM hanya menggunakan sarana usaha bersifat offline seperti pengenalan produk mulut ke mulut, catalog, brosur, pamflet serta pameran.

Rendahnya Pelaku UMKM dalam mengakses aplikasi on-line disebabkan oleh faktor internal maupun faktor eksternal. Salah satunya adalah berkaitan dengan kualitas sumber daya manusia (SDM) para pelaku usaha. Jika UMKM dapat meningkatkan kemampuan SDM dalam melakukan promosi secara online seperti website, blog, e-commerce serta 
social media (seperti: facebook, twitter, instagram, blackberry messenger) akan lebih mudah mengenalkan produk secara luas sehingga UMKM mampu bersaing di pasar domestik maupun internasional. Saat ini teknologi informasi menjadi bagian tak terpisahkan dari masyarakat, terutama di kota-kota besar, tak terkecuali di Kota Jambi. Provinsi Jambi khususnya Kota Jambi sedang dalam proses menuju masyarakat yang berorientasi digital. Perkembangan jumlah UMKM setiap tahunnya terus mengalami peningkatan. Meskipun jumlah UMKM meningkat tetapi masih banyak hambatan yang ditemui salah satunya adalah masalah pemasaran hasil produksi. Data secara pasti mengenai berapa jumlah pelaku UMKM yang sudah menggunakan digital ekonomi dalam kegiatan usahanya untuk Kota Jambi belum ada. Namun berdasarkan dari fakta yang ditemui di lapangan ternyata masih banyak pelaku usaha yang belum memanfaatkan digital ekonomi dalam pengembangan usahanya. Kebanyakan UMKM hanya menggunakan sarana usaha bersifat offline seperti pengenalan produk mulut ke mulut, catalog, brosur, pamflet serta pameran.

Dari hasil riset Deloitte (2015) hanya sekitar 9\% dari UMKM Indonesia yang telah menjalankan bisnis melalui platform ecommerce formal dan 36\% UMKM masih belum menggunakan teknologi informasi sama sekali. Pemanfaatan digital oleh UMKM dapat meningkatkan pendapatan hingga 38\% secara umum dan mendorong pertumbuhan ekonomi sebesar $2 \%$.

Berdasarkan kondisi dan gambaran diatas, ditemukan masalah yaitu adanya kesenjangan antara logika dan fakta yang terjadi antara pelaku UMKM terhadap pemanfaatan digital ekonomi. Oleh karena itu dirumuskan: 1).Bagaimana karakteristik individu dan karakteristik usaha pelaku UMKM di Kota Jambi terhadap penggunaan aplikasi online, 2).Faktor-faktor apakah yang mempengaruhi penggunaan aplikasi on-line pada pelaku UMKM Kota Jambi

\section{METODE}

\section{Populasi dan Sampel}

Populasi dalam penelitian ini adalah seluruh pelaku UMKM di Kota Jambi sebanyak 13.016. Penentuan besarnya jumlah sampel berdasarkan Purposive Sampling dengan rumus Slovin dengan dispersi 10\% untuk menghasilkan jumlah sampel sebanyak 105 responden.

\section{Alat analisa}

Untuk menganalisis faktor-faktor yang mempengaruhi penggunaan digital ekonomi pada pelaku UMKM di Kota Jambi digunakan analisis Regresi Logistik Biner. Juanda (2009) menjelaskan untuk menduga model regresi logistik ganda (multiple logistic regression model) dengan $\mathrm{k}-1$ peubah bebas, model regresi logistik dibentuk dengan menyatakan nilai $\mathrm{P}(\mathrm{Y}=1|\mathrm{x}|=$ sebagai $\mathrm{P}(\mathrm{x})$ maka logit dari model regresi logistik gandanya :

$$
\operatorname{Ln}\left(\frac{P i}{1-P i}\right)=Z i=\beta o+\beta_{1} X_{1 i}+\beta_{2} X_{2 i}+\cdots+\beta_{k} X_{k i}
$$

dan model regresi logistik gandanya:

$$
\mathrm{Pi}=\frac{1}{1+e^{-Z i}}=\frac{e^{-Z i}}{1+e^{Z i}}
$$


Secara umum jika sebuah peubah berskala nominal atau ordinal mempunyai $\mathrm{k}$ kemungkinan nilai, maka diperlukan k-1 peubah boneka (dummy variable), sehingga model transformasi logitnya menjadi:

$$
\mathrm{Zi}=\beta_{1}+\beta_{2} X_{2 i} \ldots+\sum_{u=1}^{k j-1} \beta j u D j u+\beta_{k} X_{k}
$$

Dimana:

u $\quad: 1,2,3 \ldots, \mathrm{kj}-1$

Dju : kj-1 peubah boneka

Bju : koefisien peubah boneka

$\mathrm{Xj} \quad$ : peubah bebas ke-j dengan tingkatan $\mathrm{kj}$

Selanjutnya untuk menganalisis faktor-faktor yang mempengaruhi penggunaan digital, maka digunakan model yang dikembangkan dari persamaan (3.2) sebagai berikut :

$\begin{aligned} \operatorname{Ln}\left(\frac{P i}{1-P i}\right)= & \beta o+\beta_{1 D 1} L O K 1+\beta_{1 D 2} L O K 2+\beta_{2} D P L+\beta_{3} D K M+\beta_{4 D 1} A G E 1+\beta_{4 D 2} A G E 2+ \\ & \beta_{5 D 1} E D U 1+\beta_{5 D 2} E D U 2+\beta_{5 D 3} E D U 3+\beta_{6 D 1} J U S 1+\beta_{6 D 2} J U S 2+\beta_{7} D K I+e i\end{aligned}$

Dimana :

$$
\beta_{5 D 1} E D U 1+\beta_{5 D 2} E D U 2+\beta_{5 D 3} E D U 3+\beta_{6 D 1} J U S 1+\beta_{6 D 2} J U S 2+\beta_{7} D K I+e i
$$

$\mathrm{P}_{i} \quad=$ probabilita pelaku UMKM menggunakan aplikasi online

$\left(1-\mathrm{P}_{i}\right)=$ probabilita pelaku UMKM tidak menggunakan aplikasi online

$\mathrm{EDU}=$ jenjang pendidikan formal pelaku usaha, yang dikelompokkan dalam 4 kategori dengan kategori dasar tamat SD dengan nilai sebagai berikut :

$1=$ Tamat SD

$2=$ Tamat SLTP

$3=$ Tamat SLTA

$4=$ Tamat Perguruan Tinggi

AGE = Umur dibagi dalam 3 kategori (tahun)

$1=(20-34$ tahun $)$

$2=(35-49$ tahun $)$

$3=(50-64$ tahun $)$

DPL = Dummy pelatihan IT ( $1=$ ada, 0 lainnya $)$

DJU = Dummy jenis usaha

DJU1 = Jenis usaha 1 ( 1 = dagang dan ritel, 0 lainnya $)$

DJU2 = Jenis usaha $2(2=$ jasa, 0 lainnya $)$

DJU3 = Jenis usaha 3 ( $3=$ pengolahan, 0 lainnya $)$

DIU = Dummy izin usaha $(1=$ ada, 0 lainnya $)$

LOK = Jarak lokasi usaha dengan pusat pasar kota $(\mathrm{km})$

$1=$ jarak $0-2$

$2=$ jarak $2-4$

$3=$ lebih dari 4

DKM $=$ Dummy kemitraan $(1=$ ada, $0=$ lainnya $)$

$\mathrm{DKI}=$ Dummy kepemilikan internet $/ \mathrm{WiFi} \quad(1=$ ada, $0=$ lainnya $)$

$\beta 1, \ldots, \beta 7=$ Koefisien mengukur perubahan probabilitas logistik ketika terjadi perubahan satu unit Xi.

Estimasi model logit dilakukan dengan metode maximum likelihood. Interprestasi koefisien untuk model regresi logistik biner dapat dilakukan dengan menggunakan nilai rasio oddsnya. Odd rasio bisa didefinisikan sebagai berapa kali kemungkinan pilihan 1 
diantara individu dengan $\mathrm{x}=1$ dibandingkan diantara individu dengan $\mathrm{x}=0$. Adapun Odd rasio adalah sebagai berikut: (Juanda, 2009)

$\Psi=\frac{e^{\alpha+\beta} /\left(1+e^{\alpha+\beta}\right)}{1 /\left(1+e^{\alpha+\beta}\right)} / \frac{e^{\alpha} /\left(1+e^{\alpha}\right)}{1 /\left(1+e^{\alpha}\right)}=e^{\beta}$

\section{HASIL DAN PEMBAHASAN}

\section{Karakteristik responden}

Responden dalam penelitian ini adalah pemilik UMKM di Kota Jambi yang dipilih secara purposive sampling. Karakteristik responden meliputi jenis kelamin, usia, pendidikan terakhir, jenis usaha dan lokasi usaha. Pada Tabel 1 menunjukkan mayoritas responden berusia 35-49 tahun (62,86\%), berjenis kelamin perempuan 56,19\% dengan tingkat pendidikan terakhir SLTA sederajat 46 responden $(43,81 \%)$. Jenis usaha responden sebagian besar pengolahan makanan $(41,90 \%)$, jasa $(39,05 \%)$ dan fashion $(19,05 \%)$. Lokasi usaha responden diukur dari jarak tempat usaha dengan pusat perbelanjaan pasar yaitu Kecamatan Pasar. Dari hasil penelitian ada 53 responden (50,48\%) yang mempunyai lokasi usaha dengan jarak lebih dari $4 \mathrm{~km}$.

Tabel 1. Karakteristik Pelaku UMKM

\begin{tabular}{|c|c|c|}
\hline Karakteristik & Jumlah & $(\%)$ \\
\hline \multicolumn{3}{|l|}{ Jenis Kelamin } \\
\hline Laki-laki & 46 & 43,81 \\
\hline Perempuan & 59 & 56,19 \\
\hline \multicolumn{3}{|l|}{ Usia (Tahun) } \\
\hline $20-34$ & 24 & 22,85 \\
\hline $35-49$ & 66 & 62,86 \\
\hline $50-64$ & 15 & 14,29 \\
\hline \multicolumn{3}{|l|}{ Pendidikan Terakhir } \\
\hline $\mathrm{SD} /$ sederajat & 15 & 14,29 \\
\hline SLTP/sederajat & 32 & 30,47 \\
\hline SLTA/ sederajat & 46 & 43,81 \\
\hline Sarjana & 12 & 11,43 \\
\hline \multicolumn{3}{|l|}{ Jenis Usaha } \\
\hline Fashion & 20 & 19,05 \\
\hline Jasa & 41 & 39,05 \\
\hline Olahan makanan & 44 & 41,90 \\
\hline \multicolumn{3}{|l|}{ Lokasi Usaha (km) } \\
\hline $0-2$ & 28 & 26,67 \\
\hline $2-4$ & 24 & 22,85 \\
\hline c. $>4$ & 53 & 50,48 \\
\hline
\end{tabular}

Sumber : Data diolah, 2019

\section{Uji overall model fit}

\section{Uji rasio likelihood}

Uji rasio likelihood digunakan untuk mengetahui apakah semua variable tersebut diatas saling mempengaruhi dilihat dari nilai Omnibus test sebagai berikut : 
Tabel 2. Omnibus tests of model coefficients

\begin{tabular}{llrll}
\hline & & Chi-square & Df & Sig. \\
\hline Step 1 & Step & 40.625 & 12 & .000 \\
& Block & 40.625 & 12 & .000 \\
& Model & 40.625 & 12 & .000 \\
\hline
\end{tabular}

Sumber : Data diolah, 2019

Nilai Chi Square sebesar 40.625 degree of freedom $(\mathrm{df})=12$ dengan p_value (Sig) $0,000<0,05$, dapat disimpulkan bahwa variabel-variabel tersebut signifikan mempengaruhi penggunaan digital ekonomi.

\section{Uji kecocokan model}

Uji kecocokan model dengan data menggunakan uji Hosmer dan Lemeshow. Uji ini digunakan untuk mengevaluasi cocok tidaknya model dengan data.

Tabel 3. Hosmer and lemeshow test

\begin{tabular}{cccc}
\hline Step & Chi-square & Df & Sig. \\
\hline 1 & 4.669 & 7 & .700 \\
\hline
\end{tabular}

Sumber : Data diolah, 2019

Berdasarkan Tabel 3 menunjukkan nilai Hosmer dan Lemeshow p-value (sig) lebih besar dari 0,05 , sehingga Ho diterima , secara statistik tidak terdapat perbedaan yang signifikan antara model dengan nilai observasi, sehingga model sudah fit dengan data.

\section{Estimasi parameter model}

Pada Tabel klasifikasi 2x2 menjelaskan bahwa 105 pelaku UMKM di Kota Jambi yang menggunakan aplikasi digital ekonomi diprediksi ada 49 orang dan yang tidak menggunakan sebanyak 56 orang. Hasil observasi pelaku UMKM yang menggunakan digital ekonomi sebanyak 39 orang. Jadi ketepatan prediksi untuk pelaku UMKM yang menggunakan digital ekonomi $79,6 \%$. Pelaku usaha yang tidak menggunakan digital ekonomi diprediksi sebanyak 52 orang dan hasil observasi ada 42 orang. Artinya keakuratan prediksi untuk pelaku usaha yang tidak menggunakan digital ekonomi sebesar $75.0 \%$. Jadi dapat disimpulkan keakuratan klasifikasi model regresi logistic yang digunakan cukup baik karena mampu memprediksi dengan benar 78,8\% kondisi yang terjadi.

Tabel 4. Classification tabel

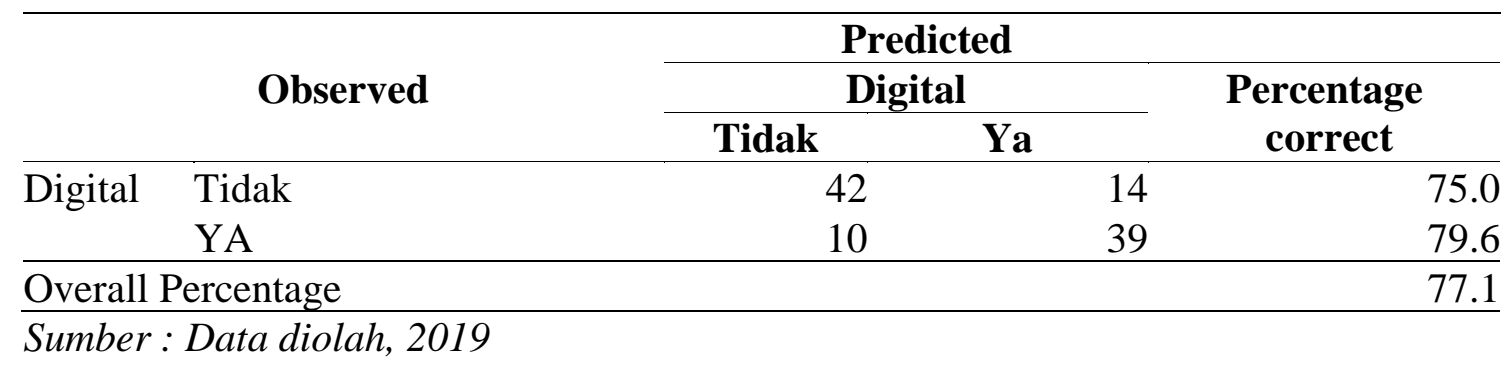




\section{Model regresi logistik}

Berdasarkan hasil penelitian diperoleh model faktor-faktor yang mempengaruhi penggunaan digital ekonomi adalah variabel pelatihan teknologi informasi, kemitraan, umur, jenis usaha dan kepemilikan jaringan internet. Variabel lokasi usaha dan pendidikan tidak berpengaruh secara signifikan.

Tabel 5. Variables in the equation

\begin{tabular}{|c|c|c|c|c|c|c|c|}
\hline & & B & S.E. & Wald & df & Sig. & $\operatorname{Exp}(B)$ \\
\hline \multirow[t]{17}{*}{ Step $1^{\mathrm{a}}$} & LOK & & & 2.797 & 2 & .247 & \\
\hline & LOK(1) & 916 & .734 & 1.558 & 1 & .212 & 2.498 \\
\hline & LOK(2) & 1.077 & .662 & 2.643 & 1 & .104 & 2.935 \\
\hline & DPL & 1.404 & .556 & 6.380 & 1 & .012 & 4.073 \\
\hline & DKM & 1.211 & .587 & 4.263 & 1 & .039 & 3.357 \\
\hline & AGE & & & 3.466 & 2 & 177 & \\
\hline & AGE(1) & -1.535 & .944 & 2.675 & 1 & .102 & .214 \\
\hline & AGE(2) & -1.543 & .639 & 4.350 & 1 & .047 & .215 \\
\hline & EDU & & & 8.836 & 3 & .032 & \\
\hline & EDU(1) & 1.020 & .821 & 1.546 & 1 & .214 & .360 \\
\hline & $\operatorname{EDU}(2)$ & 1.298 & .866 & 4.734 & 1 & .021 & 3.662 \\
\hline & EDU(3) & 1.271 & .993 & 4.603 & 1 & .034 & 3.564 \\
\hline & JUS & & & 6.592 & 2 & .037 & \\
\hline & $\mathrm{JUS}(1)$ & 1.576 & .626 & 6.339 & 1 & .012 & 4.834 \\
\hline & JUS(2) & 1.644 & .559 & 5.687 & 1 & .001 & 5.176 \\
\hline & DKI & 1.907 & .807 & 5.584 & 1 & .018 & 6.731 \\
\hline & Constant & -2.306 & 1.256 & 3.367 & 1 & .067 & .100 \\
\hline
\end{tabular}

a. Variable(s) entered on step 1: LOK, DIU, DKM, AGE, EDU, JUS, DKI.

Sumber : Data diolah, 2019

Faktor-faktor yang mempengaruhi penggunaan digital ekonomi pada pelaku usaha mikro, kecil dan menengah di Kota Jambi

\section{Lokasi usaha (LOK)}

Dalam dunia bisnis pemilihan lokasi usaha merupakan salah satu faktor yang mempengaruhi kesuksesan sebuah usaha. Lokasi usaha yang strategis dan dekat dengan pusat keramaian merupakan suatu modal atau nilai tambah dalam suatu usaha. Pada penelitian ini lokasi usaha diukur dari jarak lokasi usaha pemilik UMKM dengan pusat perbelanjaan di Kecamatan Pasar Kota Jambi. Berdasarkan hasil penelitian menunjukkan tidak ada perbedaan yang signifikan pelaku UMKM dalam penggunaan digital ekonomi berdasarkan lokasi usaha.

\section{Pelatihan tehnologi informasi (DPL)}

Aspek pelatihan informasi dan tehnologi (IT) sangat penting untuk mempersiapkan sumber daya manusia yang terampil dalam menghadapi tantangan dan pemanfaatan tehnologi dan informasi. Dengan adanya pelatihan IT diharapkan pelaku UMKM 
memperoleh informasi dan pengembangan wawasan yang sudah dimiliki. Hasil penelitian ini menunjukkan ada perbedaan pelaku usaha dalam penggunaan digital ekonomi berdasarkan pelatihan IT. Pelaku usaha yang pernah mengikuti pelatihan IT mempunyai probabilitas 4,073 (odd ratio) lebih besar dalam penggunaan digital ekonomi dibandingkan dengan yang belum pernah mengikuti pelatihan IT. Ini sejalan dengan penelitian yang dilakukan Adnan Mustafa AlBar \& Md. Rakibul Hoque (2017) yang menyatakan bahwa salah satu faktor yang mempengaruhi adopsi tehnologi informasi pada usaha kecil adalah pengetahun ICT dari UMKM.

\section{Kemitraan (DKM)}

Kemitraan merupakan suatu program untuk meningkatkan kemampuan usaha kecil agar menjadi tangguh dan mandiri melalui pemanfaatan dana dari bagian laba Badan Usaha Milik Negara (BUMN). Kemitraan bertujuan untuk meningkatkan akses pasar, akses terhadap permodalan dan peningkatan kemampuan organisasi dan manajemen. Ada beberapa BUMN yang pernah menyalurkan kemitraan kepada UMKM di Kota Jambi dalam bentuk Kredit Usaha Rakyat (KUR) dan Program Kemitraan dan Bina Lingkungan (PKBL) seperti : Bank 9 Jambi, PT Persero Nusantara VI, PT Pusri, PT.Taspen, PT.Posindo, PT.PLN, Bank Indonesia dan PT.Jasa Raharja. Dari hasil penelitian menunjukkan ada perbedaan yang signifikan (sig $0.039<0.05)$ pelaku UMKM dalam penggunaan digital ekonomi berdasarkan kemitraan. Pelaku UMKM yang pernah menerima program kemitraan dari BUMN mempunyai probabilitas 3,36 kali lebih besar dalam penggunaan digital ekonomi dibandingkan dengan yang tidak mempunyai kemitraan. Hasil ini sejalan dengan penelitian yang dilakukan Wanyoike, D. M., et al (2012) bahwa perlunya kemitraan dengan lembaga institusi yang terkait untuk melatih wirausaha muda tentang cara menggunakan tehnologi dan informasi untuk mengembangkan usaha.

\section{Umur (Age)}

Umur sangat mempengaruhi kemampuan dalam melakukan kegiatan atau aktivitas seseorang. Hasil penelitian menunjukkan bahwa tidak ada perbedaan dalam penggunaan digital ekonomi berdasarkan umur antara pelaku usaha ( 20-34 tahun) dengan pelaku usaha (35-49 tahun). Namun ada perbedaan yang signifikan antara umur pelaku usaha (20-35 tahun) dengan umur pelaku usaha (50-64 tahun). Pelaku usaha dengan kategori umur 50-64 tahun mempunyai probabilita lebih kecil dalam menggunakan digital ekonomi dibandingkan dengan pelaku usaha dengan kategori umur 20-34 tahun (Odd rasio $=0,215$ ). Artinya probabilitas kemampuan dalam mengadopsi tehnologi digital ekonomi untuk pelaku usaha yang muda lebih besar.

\section{Pendidikan (Edu)}

Pendidikan dibagi dalam empat kelompok yaitu SD, SLTP, SLTA dan Perguruan Tinggi. Hasil penelitian menunjukkan bahwa tidak ada perbedaan antara pelaku usaha dengan pendidikan SD dan SMP dalam penggunaan digital ekonomi. Akan tetapi ada perbedaan yang signifikan antara tingkat pendidikan SLTA dan Perguruan Tinggi. Artinya semakin tinggi tingkat pendidikan maka probabilitas pelaku usaha dalam menggunakan aplikasi digital ekonomi juga semakin besar. Hasil penelitian ini sesuai dengan yang dilakukan Apri (2016) bahwa masih sangat sedikit UMKM yang menggunakan internet 
dalam kegiatan bisnisnya disebabkan pengetahuan yang sangat minim. Syed Zamberi Ahmad, et al (2015) juga mengungkapkan bahwa pengetahuan dan keahlian pemilik usaha merupakan salah satu faktor penentu dalam mengadopsi ICT.

\section{Jenis usaha (Jus)}

Pelaku usaha dikelompokkan menjadi tiga jenis usaha yaitu : jenis usaha fashion, jasa dan pengolahan makanan. Penelitian menunjukkan adanya perbedaan pelaku usaha dalam menggunakan aplikasi digital ekonomi berdasarkan jenis usaha. Variabel jenis usaha jasa (JUS1) mempunyai nilai Odd ratio 4,834. Artinya pelaku usaha yang bergerak dibidang jasa mempunyai probabilitas 4,834 kali lebih besar dalam menggunakan digital ekonomi dibandingkan dengan pelaku usaha yang mempunyai jenis usaha fashion. Selanjutnya nilai odd ratio untuk jenis usaha olahan makanan (JUS2) diperoleh 5,176 artinya pelaku usaha yang bergerak di bidang usaha olahan makanan mempunyai probabilitas 5,176 kali dalam menggunakan aplikasi digital dibandingkan dengan usaha fashion. Digital ekonomi dalam hal ini digunakan untuk memudahkan pelaku usaha dalam memantau dan menyediakan kebutuhan dan keinginan calon konsumen, disisi lain calon konsumen juga bisa mencari dan mendapatkan informasi produk hanya dengan cara menjelajah dunia maya sehingga mempermudah proses pencarian. Media social yang digunakan pelaku usaha sebagian besar berupa postingan foto di instagram dan facebook. Berdasarkan hasil penelitian pelaku usaha yang mempunyai usaha kuliner mempunyai probabilitas lebih besar jika dibandingkan dengan usaha fashion dan jasa. Hal ini cukup beralasan mengingat usaha kuliner ini mendominasi 43,16\% sektor UMKM. Eksistensi usaha kuliner dimedia sosial merupakan suatu keharusan karena tak bisa dipungkiri dapat membuat siapapun, kapanpun, dan dimanapun berada dengan mudahnya mengetahui informasi terkini dari usaha kuliner tersebut. Mulai dari promo diskon, menu-menu yang dijual hingga mengadakan giveaways tertent.

\section{Jaringan internet (DKI)}

Internet sudah menjadi kebutuhan primer bagi dunia usaha. Internet diharapkan dapat menjadi inspirasi para pelaku UMKM dalam memasarkan produknya dengan wilayah pemasaran yang tidak terbatas. Kemampuan tehnologi internet membuat semua pekerjaan lebih praktis, jarak dan waktu menjadi sangat efisien. Meskipun banyak manfaat dari jaringan internet, namun belum semua pelaku UMKM dapat mengakses internet dengan baik. Menurut Taylor\&Owusu (2012) salah satu kendala dalam mengadopsi internet adalah mahalnya jaringan infrastruktur telekomunikasi. Pada penelitian ini jaringan internet diukur dari ada atau tidaknya pelaku UMKM berlangganan WiFi ditempat lokasi usahanya. Hasil penelitian menunjukkan ada perbedaan yang signifikan dalam penggunaan digital ekonomi berdasarkan pemasangan WiFi. Pelaku UMKM yang berlangganan WiFi mempunyai probabilitas 6,73 kali lebih besar dalam penggunaan digital ekonomi dibandingkan dengan yang tidak berlangganan.

\section{KESIMPULAN DAN SARAN}

\section{Kesimpulan}

Secara umum belum sepenuhnya pelaku UMKM di Kota Jambi mengaplikasikan penggunaan digital ekonomi. Kegiatan usaha yang dilakukan sebagian besar masih bersifat 
konvensional yang hanya memajang produk di toko yang mereka miliki atau sesekali mengikuti pameran-pameran yang diselenggarakan oleh instansi atau dinas yang melakukan pembinaan UMKM. Pelaku usaha sebagian besar menggunakan media social sebagai sarana digital seperti Whats App,Facebook dan Black Berry Messenger untuk bertransaksi, promosi dan memasarkan produknya. Ini cukup beralasan karena selain biaya yang murah juga tidak membutuhkan keahlian khusus dalam melakukan insiasi awal.

Kendala yang sering dihadapi pelaku UMKM adalah kurangnya pemahaman mengenai pentingnya digital ekonomi, kurangnya pengetahuan mengenai tehnologi informasi dan komunikasi serta cara-cara penggunaan dan pemanfaatan media social yng baik serta pemahaman untuk menciptakan "postingan" yang menarik. Pelaku usaha sering menganggap penggunaan digital untuk marketing cukup sulit, dan merasa tidak banyak transaksi actual yang terjadi dibandingkan berjualan secara langsung.

Penggunaan digital ekonomi tidak terlepas dari factor karakteristik rumah tangga dan karakteristik usaha pelaku UMKM. Rendahnya tingkat pendidikan, umur, kemitraan, keterbatasan jaringan internet dan jenis usaha mempengaruhi pelaku usaha dalam menggunakan digital ekonomi.

\section{Saran}

Tehnologi digital diharapkan dapat meningkatkan kegiatan usaha melalui informasi produk hanya dengan cara menjelajah dunia maya yang pada akhirnya akan meningkatkan penjualan dan profit UMKM. Perlu dukungan dari pemerintah dalam bentuk kemitraan, seperti Kementerian Koperasi dan UKM yang bekerjasama dengan Kementerian Riset Tehnologi untuk mengadakan pembinaan dan pelatihan IT terhadap pelaku UMKM dalam upaya untuk meningkatkan pengembangan kualitas sumber daya manusia.

\section{DAFTAR PUSTAKA}

Adnan Mustafa AlBar \& Md. Rakibul Hoque (2017) Factors affecting the adoption of information and communication technology in small and medium enterprises: a perspective from rural Saudi Arabia, Information Technology for Development, 25(4), 715-738, DOI: 10.1080/02681102.2017.1390437

Bank Indonesia. (2010). Survei BI diakses dalam http://bi.go.id, Tanggal 20 Juli 2019, Pukul 12.30 WIB

Baron, R. A. (2003). Human resource managementand entrepreneurship: some reciprocalbenefits of closer links. Human ResourceManagement Review, 13(2), 253256.

Budianto Apri (2016) Marketing strategies model with e-commerce in improving market area of SMEs in rural District Ciamis, West Java Province, Indonesia, European Journal of Business and Management, 8(35), 92-96

Deloitte.(2015). UKM Pemicu kemajuan Indonesia : Instrumen pertumbuhan bangsa[Online].diakses pada:http://www2.deloitte.com, Tanggal 31 Agustus 2016, Pukul 10.00 WIB

Dhyah Ayu Retno Widyastuti, R. N. (2016). Literasi digital pada perempuan pelaku usaha produktif di Daerah Istimewa Yogyakarta. Jurnal ASPIKOM, 3(1), 1-15

Ishak, Effendi. (2005). Artikel: peranan informasi bagi kemajuan UKM. kedaulatan rakyat: Yogyakarta 
Jenny, C.A., and Isaac, M. (2010). Mobile phones and economic development in Africa, Journal of Economic Perspectives, 24(3), 207-232.

Juanda B. (2009). Ekonometrika pemodelan dan pendugaan. IPB Press:Bogor

Kiran V, Majumdar M, Kishore K. (2012). Innovative marketing strategies for micro, small and medium enterprises. Interdisiplinary Journal of Contemporary Research in Business 4(2): 1059-1066.

Kristiansen, S., Kimeme, J., Mbwambo, A., dan Wahid, F. (2005). Information flows and adaptation in Tanzanian cottage industries.Entrepreneurship and Regional Development, 17(5), 365-388.

Lubis,Aurora,Tona dan Junaidi. (2016). Pemanfaatan teknologi informasi pada usaha mikro kecil danmenengah di Kota Jambi Jurnal Perspektif Pembiayaan dan Pembangunan Daerah, 3(3), 2338-4603

Mbogo, M. (2010). The impact of mobile payments on the success and growth of microbusiness: The Case of M-Pesa in Kenya, Journal of Language, Technology \& Entrepreneurship in Africa,2(1), 182-203

Sudaryanto. (2011). The Need for ICT-education for manager or agribusinessman to increasing farmincome : study of factor influences on computer adoption in east java farm agribusiness. Journal of education and development (JEDICT), 7(1), 56-67

Sugiyono. (2011). Metode penelitian kuantitatif kualitatif dan $R \& D$. Alfabeta: Bandung

Syed Shah Alam, Md. Yunus Ali \& Mohd. Fauzi Mohd. Jani. (2011). An empirical study of factors affecting electronic commerce adoption among SMEs in Malaysia, Journal of Business Economics and Management, 12(2), 375-399, doi: 10.3846/16111699. 2011.576749

Syed Zamberi Ahmad, Abdul Rahim Abu Bakar, Tengku Mohamed Faziharudean \& Khairul Anwar Mohamad Zaki (2015) An empirical study of factors affecting ecommerce adoption among small- and medium-sized enterprises in a developing country: evidence from Malaysia, Information Technology for Development, 21(4), 555-572, doi: 10.1080/02681102.2014.899961

Tambunan T. (2009). UMKM di Indonesia. Ghalia Indonesia: Jakarta

Taylor, T., \& Owusu, E. D. E. (2012). Factors affecting internet and e-commerce adoption among small and medium-sized enterprise non-traditional exporters: Case studies of Ghanaian handicraft exporters. European Journal of Business and Management, 4(13), 25-37.

Wanyoike, D. M., Mukulu, E., \& Waititu, A. G. (2012). ICT attributes as determinants of e-commerce adoption by formal small enterprises in urban Kenya. International Journal of Business and Social Science, 3(23).65-74 